\title{
Deep Eutectic Solvents: An Overview of its Application as a "Green" Extractant
}

\author{
C. Andrew ${ }^{* 1}$, E.E. Etim ${ }^{1}$, O.A. Ushie ${ }^{1}$, J.N. Job ${ }^{2}$ \\ ${ }^{1}$ Department of Chemical Sciences, Federal University, Wukari, Nigeria \\ ${ }^{2}$ Department of Chemistry, Taraba State University, Jalingo
}

*Corresponding Author: C. Andrew, Department of Chemical Sciences, Federal University, Wukari, Nigeria

\begin{abstract}
The $21^{\text {st }}$ century idea of "green chemistry" is gradually changing the modern scientific research towards the use of sustainable, safe and benign solvents as alternative to volatile organic solvents which are toxic and may be hazardous. One of such novel solvent that has been proposed to replace these harmful solvents is the use of deep eutectic solvents (DESs) because of their fascinating properties which have attracted the interest of many researchers since it was proposed in 2003 with a total of about 1,553 scientific publications in this area. Their high solubility property for solutes has envisaged their application as a benign solvent for extraction of bioactive substances in plants. In this overview, we have summarized the recent research progress of DES in its application as a solvent in the extraction of bioactive compounds from plants with the view to advance the concept of using non-toxic solvent in extraction processes.
\end{abstract}

Keywords: Deep eutectic solvents, green chemistry, extraction, bioactive compounds

\section{INTRODUCTION}

Globally, there is a gradual shift in modern scientific research through the utilization of non-toxic precursor materials for solvent formulation. The $21^{\text {st }}$ century concepts of "green chemistry" forms the basis of most today's scientific research. The key idea behind this concept is to provide alternative routes that can reduce the production and utilization of harmful materials that affect both human and the environment through the use of renewable, cheap and environmentally safe precursor materials. Almost all branches of chemistry have embraced this notion since its formal emergence in the early 1990's by adhering to the twelve (12) green principles proposed by Anastas and Warmer [1]. Based on these principles, the concept of "green solvents" was proposed with the view to reduce the industrial impact on the environment by using safer and non-toxic solvents than the conventional solvents. The green solvents' concepts that were proposed for implementations were summarized by [2]. They include:

i. Replacing all volatile organic compounds (VOCs) that are used as solvents with non-volatile benign solvents, i.e. solvents that have negligible vapour pressure

ii. Replacing all hazardous solvents with one that are non-toxic and environmentally friendly

iii. Using bio-solvents that are obtained from renewable materials

Since this idea "green" was proposed in chemistry, there are considerable efforts to replace the use of toxic solvents in chemical productions and processes by finding new and benign solvents that are safe to both man and the environment. The current trends widely employed for the extraction of phytochemical and bioactive constituents from plant materials involves the use of volatile organic solvents $[3,4]$. However, most of these conventional solvents used in the extraction of plant extracts are associated with high quantity of solvent utilization with long extraction times [5], they produce unacceptable residues in extract [6], highly volatile and therefore ends up in the atmosphere or in ground water [7-12] which results in environmental pollution. In addition, the critical temperature $\left(>200{ }^{\circ} \mathrm{C}\right)$ of most of these traditional organic solvents are not suitable for isolation of bioactive compounds [13], since this may result in losing most of the volatile components in the plants. 
Therefore, in the present modern extraction processes, there are high interests to reduce or completely eliminate environmentally harmful solvents as an extraction media by considering the use of "green solvent" as an alternative due to its safe and high quality of extracts [14].

In the quest to find "greener" solvents, researchers are therefore looking for environmentally benign, less expensive, non-toxic, renewable, biodegradable, less volatile and easy to produce precursor materials in formulating solvent. And to this, a new class of novel solvent called deep eutectic solvents (DESs) was developed more than a decade ago by Andrew Abbott and his co-workers [15]. According to the Abbott group, a solid organic salts and a complexing agent when mixed in the right proportion/ratio and upon heating results in producing liquid that have freezing point lower than the individual components. In addition, the temperature of the eutectic mixture is below the boiling point of water. The lowering of freezing point (Figure 1) is brought about as a result of hydrogen bond interaction between the complexing agent and the organic salts. The earliest and most widely studied eutectic mixture is that reported by [15] consisting of choline chloride $(\mathrm{ChCl})$ and urea with melting point of $302{ }^{\circ} \mathrm{C}$ and $133{ }^{\circ} \mathrm{C}$ respectively. In this study, when the $\mathrm{ChCl}$ and urea was mixed at a molar ratio of $1: 2$ and was heated at $80{ }^{\circ} \mathrm{C}$, room temperature solvents were obtained with freezing point of $12{ }^{\circ} \mathrm{C}$.

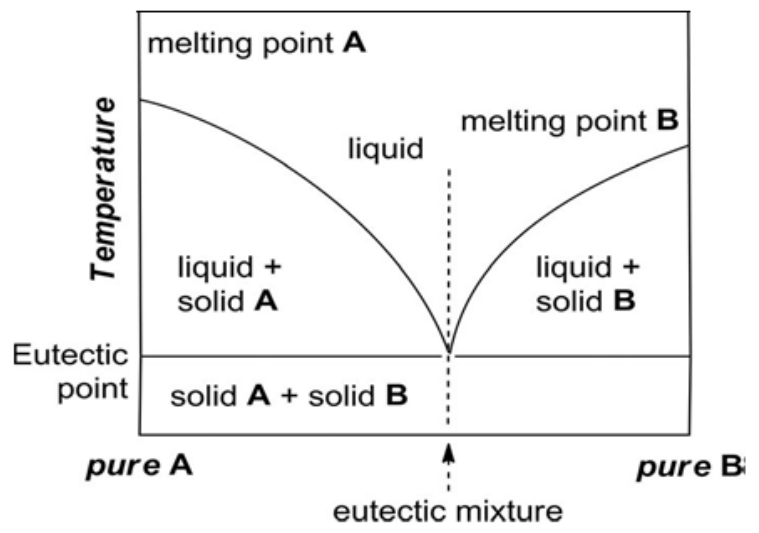

Source: [16]

Figure1. Eutectic point representation on a two component phase diagram

Since the versatile discovery of the applications of DESs by the Abbott group, they have been termed as "green solvent" because their properties (table 1) fulfil most of the twelve principles of green chemistry as outlined by Anastas and Warmer [1]. Some of the outstanding properties of DES include; wide electrochemical window, negligible volatility, non-flammable, non- toxic, consists of cheap and biodegradable components that can be found from natural occurring materials.

Table1. Properties of DES in comparison with some of the principles of green chemistry

\begin{tabular}{|l|l|l|}
\hline S/No & Principles of Green Chemistry & Properties of DES \\
\hline 1 & Atom economy & $\begin{array}{l}\text { The atom economy of DES is 100\% as its formulation does not } \\
\text { involve chemical reactions [17, 27]. Thus, synthesis of DES } \\
\text { involves the incorporation of 100\% of the starting materials in } \\
\text { the final product since DES formation involves simply mixing } \\
\text { the basic components without lost of any atom. In addition, no } \\
\text { waste or by-products are generated during the preparation of } \\
\text { deep eutectic solvents. }\end{array}$ \\
\hline 2 & $\begin{array}{l}\text { Less hazardous constituents and } \\
\text { products }\end{array}$ & $\begin{array}{l}\text { Nearly all the precursors used in the formulation DESs are non- } \\
\text { toxic. For instance, choline chloride (vitamin B } \text { }_{4} \text { is non-toxic } \\
\text { which is one of the most widely used components of DES and is } \\
\text { approved by the European Food Safety Authority either as an } \\
\text { additive in chicken feed as well an essential micronutrient and } \\
\text { human nutrients [29, 30]. }\end{array}$ \\
\hline 3 & Use of renewable feedstock & $\begin{array}{l}\text { The components of DES are generally obtained from inexpensive } \\
\text { and renewable materials e.g. quaternary ammonium salts are } \\
\text { readily available. }\end{array}$ \\
\hline 4 & Design for degradation & $\begin{array}{l}\text { Most of the components of DES are biodegradable [31] and as } \\
\text { such do not persist in the environment for a longer period of } \\
\text { time. For example, cholinium alkanoates based DESs are } \\
\text { environmentally benign and biodegradable [32, 33]. }\end{array}$ \\
\hline
\end{tabular}


Moreover, these novel solvents can be formulated by simply mixing the appropriate components with $100 \%$ atom economy without further purification [17]. Owing to their physical properties, many researchers have reported that DESs have feasible industrial applications [18-23]. As reviewed by Zhang et al., [24] and Tang et al., [25], there are many potential areas to which DESs can be applied. Their outstanding properties have been proposed as alternatives to most conventional solvents [26].

Generally, there is high interest by researchers in recent times and significant increase in the number of studies exhibited by scholars as evidenced in the DES publications in the literature [27, 28]. In order to highlight the growing interest of DES as green solvents, the authors have searched through Web of Science citation database and a total of 1,553 publications with the word "deep eutectic solvent" were obtained as at $23^{\text {rd }}$ August, 2017. Out of which $120,59,22$, and 5 are respectively reviewed articles, proceedings paper, meeting abstracts and correction and the rest $(1,374)$ are research findings in the area of DES. However, readers should note that the Web of Science database will always be updating once there are articles published with the word "deep eutectic solvent" and therefore the number of citations will be higher after the date quoted since more articles are possible to be published in this area. This clearly indicates that since the period from 2003 i.e. the year in which the Abbott group proposed for the first time the versatile use of DES to the present time, there is a wide acceptability for deep eutectic solvent as a green solvent in alternative to conventional solvents.

In figure 2, the number of published articles from $2003-23^{\text {rd }}$ August, 2017 is presented. It is clear from this figure that the number of articles keeps increasing year after year and this could be attributed to a number of factors. For instance, the simplicity in formulating the solvents, its nontoxicity and as well the interest in exploring it for potential application in many areas of chemistry as benign solvent.

It is worth to mention to readers that, there were dearth of research reports with regard to eutectic mixtures in the literature before the work of Abbott and co-workers in 2003. In this review, the authors have focused only on the description of the utilization of DES as a green solvent in the extraction/isolation of bioactive components from plants.

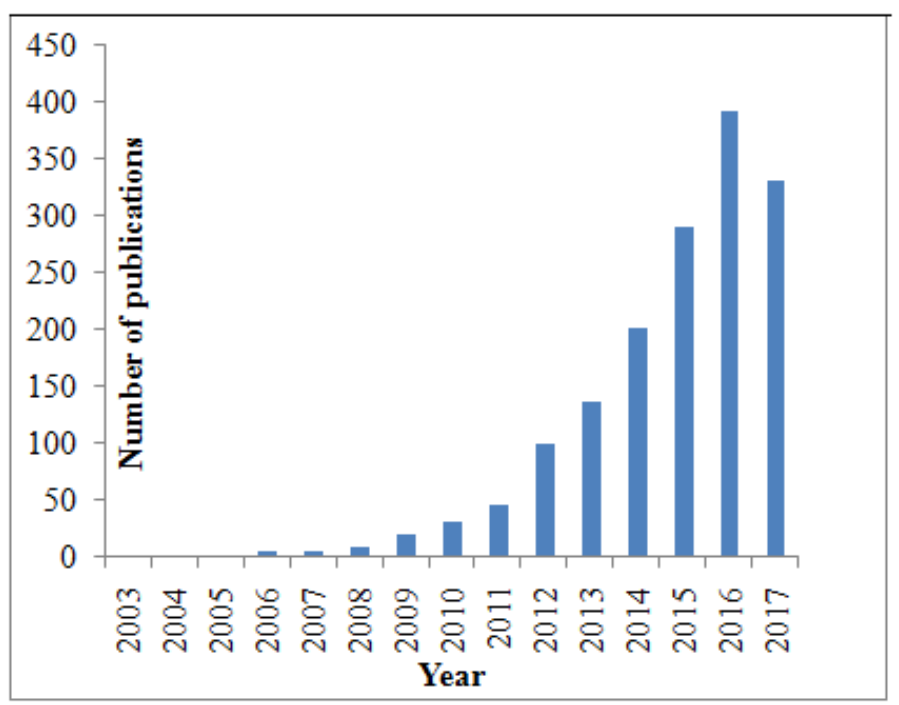

Figure2. Recent trends in DES publications. Source: Web of Science Citation Database, $23^{\text {rd }}$ August, 2017

\section{DeEP EuteCTIC SOlVENT AS A NOVEl BENIGN EXTRACTANT FOR BIOACTIVE COMPOUNDS IN PLANTS}

Solvent extraction remains one of the traditional basic ways of isolating bioactive compounds from plants. The process is based on mixing the plant samples with a suitable solvent using any of the extraction methods. There are several extraction techniques that have been reported in the literature such as ultrasound-assisted extraction (UAE), pressurized liquid extraction (PLE), microwave-assisted extraction (MAE), heat reflux extraction (HRE) and headspace-solvent micro-extraction (HS-SME) [34-39]. Traditional solvents commonly used are mostly volatile organic compounds (VOCs). However, there are environmental concerns due to their toxicity as well as low yield resulting from the use of VOCs as an extraction media. Hence, such class of solvents limits their application in areas 
where purity of products is vital such as in pharmaceutical and food industry. This has necessitated the search of sustainable and benign solvents as extractants. To this, deep eutectic solvents have emerged as an alternative due to the aforementioned desirable properties that qualify them as green solvent (table 1). Furthermore, there is suggestion in the literature that for water insoluble compounds, DESs have a superior dissolution and extraction ability [24]. This has been confirmed where the solubility of rutin in DESs was found to be at least 50-fold higher than in water [40]. In this section, the authors intend to summarise some of the scientific findings relating to the use of DES as a green solvent for the separation of phytochemical components from plants. Though, it has been reported that there are relatively few number of articles in the literature of DESs used as media for the extraction of natural products in plants [41]. However, the authors have tried in this review to present the available literature to them on DESs application as solvent in the extraction of plant components.

Different types of DESs have been reported by [42] for the extraction of phenolic metabolites from safflower. A significant amount (between 75\% and 97\%) of phenolic metabolites was recovered from the DES. Hydrogen bonding occurring between DES molecules and phenolic compounds according to the authors was responsible for the high extraction efficiency. In a similar manner, Bi and co-workers [43] studied the application of seven alcohol-based DESs to extract myricetin and amentoflavone (flavonoids) from Chamaecyparis obtuse. In this study, $\mathrm{ChCl} / 1$, 4-butanediol DES at a molar ratio of 1:5 was found to be the best DES to extract myricetin and amentoflavone. It was further observed that the use of DESs enhanced the solubility of flavonoids, which indicates the extraction efficiency of DES for bioactive compounds from plant materials. Tang et al., [38], have used headspace-solvent microextraction (HS-SME) as an extraction technique to extract three terpenoids from chamaecyparis obtuse leaves using deep eutectic solvents which was based on $\mathrm{ChCl} /$ ethylene glycol at different ratios. The terpenoids were recovered at a very high percentages ranging between $79.4-103 \%$.

Zhao et al., [31] investigated the extraction of flavonoid from the flower buds of Sophora japonica using several choline based deep eutectic solvents. It was found that eutectic solvents based on choline/triethylene glycol can be efficiently used as a potential green solvent for the removal of rutin in sophora japonica with an extraction efficiency of $194.17 \pm 2.31 \mathrm{mg} \cdot \mathrm{g}^{-1}$. In an attempt to broaden the usage of DESs in the extraction of bioactive compounds from plants, Duan et al., [44] have used many choline chloride, betaine (Bet)-, and L-proline (Pro)-based DESs to extract alkaloids, phenolic acids, saponins, flavonoids and anthraquinones from five Chinese herbal medicines (Berberidis Radix, Epimedii Folium, Notoginseng Radix et Rhizoma, Rhei Rhizoma et Radix, and Salviae Miltiorrhizae Radix et Rhizoma).Their findings showed that most of the DESs used were more effective in extracting alkaloids than anthraquinones. The researchers concluded that the extraction ability of DES may be associated with their physicochemical properties, including hydrogen bonding interactions, polarity, viscosity, and $\mathrm{pH}$. In a review article by [28], the authors pointed out that polarity is an important property of solvent for its ability to dissolve solutes. However, it was found that there are little available information with regards to the polarity of DESs in the literature. In their studies, Nisar et al., [45] have used deep eutectic solvent composed of choline chloride and glycerol to extract some phytochemicals from Catharanthus roseus roots, stems, leaves, and flower petal. The results indicated the presence of many active chemical constituents including alkaloids, saponins, steroids, terpenoids, phenol, flavanoids and reducing sugar.

Recently, Piemontese et al., [46] have compared the extraction efficiency of volatile organic solvents and deep eutectic solvents to extract ochratoxin A in wheat and derived products. It was discovered that DES based on choline chloride with a mixture of urea and glycerol can be an excellent substitute for conventional solvents in the extraction of ochratoxin A. It has been shown that deep eutectic solvents can be used as an additive of conventional solvents to extract bioactive compounds from plants. For instance, Park et al., [47] have used DESs based on tetramethyl ammonium chloride/ urea (molar ratio of 1:4) as an additive to methanol to extract two active compounds (chlorogenic and caffeic acids) from Herba Artemisiae Scopariae. Under optimal experimental conditions, about 9.35 $\mathrm{mg} / \mathrm{g}$ of chlorogenic acid and $0.31 \mathrm{mg} / \mathrm{g}$ of caffeic acid were extracted. Tang et al., [48] have further demonstrated the use of DES as an additive to extract three flavones (quercetin, myricetin and amentoflavone) from Chamaecyparis obtusa leaves. Methanol was also used as a conventional solvent and when the DES was added as an additive, the author observed a remarkable increase in the amounts of the flavones extracted. Thus, it can be concluded that using DES as an extraction additives can affect solvent properties. 
Utilizing a microwave-assisted extraction (MAE) technique with a series of choline chloride based DESs, Li et al., [49] have extracted catechins from the leaves of camellia sinensis. They found that DESs made of $\mathrm{ChCl}$ and lactic acid possessed the highest ability to extract catechins from the plant sample. In that study, the recovery yields were in the range $75.2-86.1 \%$. The extraction of phenolic acids (rosmarinic acid and salviaflaside) in Prunella vulgaris was carried out by [50]. In this study, an alcohol based DESs were used as the media solvent at different extraction conditions. About $3.658 \mathrm{mg}$ $\mathrm{g}^{-1}$ and $1.049 \mathrm{mg} \mathrm{g}^{-1}$ of rosmarinic acid and salviaflaside respectively were extracted. The results obtained in this work proved that the amount of rosmarinic acid and salviaflaside extracted were higher compared to the previously reported extraction technique and conventional solvents in the findings of Chen et al., [51-53]. Nam et al., [54] have compared the extraction efficiency of DES with conventional solvent (methanol) to extract bioactive compounds from a biomass. The investigation showed that DES based solvent was more effective than methanol in extracting quercetin, kaempferol and isorhammetin glycosides from flos sophorae. The antioxidant activity measured in this study further revealed that DES based solvent have the ability to enhance the bioactivity of the extracts and the recovery of flavanoids was far much higher than the use of methanol as conventional solvent.

Generally, DES tends to exhibit a very high viscosity and thus will limit their solubility property to extract bioactive compounds in plants. However, it has been suggested that the reduction of the viscosity via addition of water can lower the viscosity and hence increase their solubility behaviour [55]. A few numbers of studies have reported the addition of water in other to reduce the viscosity of DES and these have significantly enhanced the extraction yields. For instance, the viscosity of ChCloxalic acid based DES was reduced by adding $25 \%$ of water and used to extract flavanoids from grape skin. It was found that the mixture produced a maximum yield of the bioactive compounds where a high amount of flavanoids $((+)$ catechin) was obtained in comparison with pure ChCl-oxalic acid DES [56]. In a further study, a microwave-assisted extraction method was reported by [57] to extract phenolic compounds from cajanus cajan leaves using different types of DESs. Addition of $20 \%(\mathrm{v} / \mathrm{v})$ of water was found to increase the extraction efficiency of the phenolic compounds from 40 to $60 \%$ owing to decrease in the viscosity of the eutectic mixture.

\section{CONCLUSION}

Since from the year (2003) in which the Abbott group proposed the versatile use of DES to the present time, there is a wide acceptability for it as a green solvent and therefore be an alternative to conventional solvents. In this overview, we have presented that DES has the potential to replace conventional organic solvents in the extraction of bioactive compounds from plants. Though, there are very few numbers of articles published in the use of the solvent for extraction. We suggest that the concept of using non-toxic solvents as well as its precursors should be the paramount priority of modern chemists.

\section{REFERENCES}

[1] Anastas P.T., and Warner J.C., Green Chemistry: Theory and Practice; Oxford University: New York, NY, 1998.

[2] Anastas, P. T., Green Solvents Set II; Wiley-VCH Verlag GmbH: Berlin, Vol. 4-6, boxed set, 2010.

[3] Duan L., Guo L., Liu K., Liu E.H., Li P., Characterization and classification of seven Citrus herbs by liquid chromatography-quadrupole time-of-flight mass spectrometry and genetic algorithm optimized support vector machines. J. Chromatography A, 1339, 118-127, (2014).

[4] Bi W., Tian M., Row K.H., Evaluation of alcohol-based deep eutectic solvent in extraction and determination of flavonoids with response surface methodology optimization. J. Chromatogr. A, 1285, 22-30 (2013).

[5] Bubalo M.C., Curko N., Tomaševic M., Ganic' K.K., Redovnikovic I.R., Green extraction of grape skin phenolics by using deep eutectic solvents, Food Chemistry, 200, 159-166 (2016).

[6] Puranik, S.B., Sanjay Pai, P.N., Rao G.K., Int. J. Appl. Res. Nat. Prod. 2, 32-46 (2009).

[7] Concepción Jiménez-González D. J.C.C., "Green Chemistry and Engineering-A Practical Design Approach,” John Wiley \& Sons Inc., Hoboken, pp. 3-39 (2011).

[8] Ahluwalia V.K., "Green Chemistry, Environmentally Benign Reaction," CRC Press \& Francis Group, Boca Raton (2009).

[9] Sheldon R.A., "Fundamentals of Green Chemistry: Efficiency in Reaction Design," Chemical Society Reviews, 41(4), 1437 (2012). 
[10] Dunn P.J., “The Importance of Green Chemistry in Process Research and Development," Chemical Society Reviews, 41(4), 1452 (2012).

[11] Ghernaout D., Ghernaout B., and Naceur M.W., "Embodying the Chemical Water Treatment in the Green Chemistry-A Review," Desalination, 271(1), 1 (2011).

[12] Capello C., Fischer U., and Hungerbuhler K., "What Is a Green Solvent? A Comprehensive Framework for the Environmental Assessment of Solvents," Green Chemistry, 9(9), 927 (2007).

[13] Liley P.E., Thomson G.H., Friend D.G., Daubert T.E., Buck E., Physical and Chemical Data. In Perry's Chemical Engineers' Handbook, 7th ed.; Perry, R.H., Green, D.W., Maloney, J.O., Eds.; McGrawHill: New York, NY, USA, Section 2 (1999).

[14] Chemat F., Maryline Abert Vian M.A., and Cravotto G., Green extraction of natural products: Concept and principles, Int. J. Mol. Sci. 13, 8615 (2012).

[15] Abbott A.P., Capper G., Davies D.L., Rasheed R.K., Tambyrajah V., Novel solvent properties of choline chloride/urea mixtures. Chem. Commun. 1, 70 (2003).

[16] Smith E.L., Abbott A.P., Ryder K.S., Deep Eutectic Solvents (DESs) and Their Applications. Chemical Reviews, 114(21), 11060 (2014).

[17] Singh B., Lobo H., Shankarling G., Selective N-alkylation of aromatic primary amines catalyzed by biocatalyst or deep eutectic solvent. Catal. Lett. 141, 178 (2011).

[18] Shahbaz K., Mjalli F.S., Hashim M.A., ALNashef I.M., Using Deep Eutectic Solvents for the Removal of Glycerol from Palm Oil- Based Biodiesel. J. Appl. Sci. 10, 3349 (2010).

[19] Abbott A.P., El Ttaib K., Frisch G., McKenzie K.J., Ryder K.S., Electrodeposition of copper composites from deep eutectic solvents based on choline chloride. Phys. Chem. Chem. Phys. 11, 4269 (2009).

[20] Kareem M.A., Mjalli F.S., Hashim M.A., AlNashef I.M., Liquid-liquid equilibria for the ternary system (phosphonium based deep eutectic solvent-benzene-hexane) at different temperatures: A new solvent introduced. Fluid Phase Equilib. 314, 52 (2012).

[21] Kareem M.A., Mjalli F.S., Hashim M.A., Hadj-Kali M.K.O., Bagh F.S.G., Alnashef I.M., Phase equilibria of toluene/heptane with tetrabutylphosphonium bromide based deep eutectic solvents for the potential use in the separation of aromatics from naphtha. Fluid Phase Equilib. 333, 47 (2012).

[22] Abbott A.P., Capper G., McKenzie K.J., Ryder K.S., Electrodeposition of zinc-tin alloys from deep eutectic solvents based on choline chloride. J. Electroanal. Chem. 599, 288 (2007).

[23] Abbott A.P., Barron J.C., Frisch G., Ryder K.S., Silva A.F., The effect of additives on zinc electrodeposition from deep eutectic solvents. Electrochim. Acta., 56(14), 5272 (2011).

[24] Zhang Q ., Vigier K.D.O., Royer S ., Jérôme F ., Deep eutectic solvents: syntheses, properties and applications. Chem. Soc. Rev., 41, 7108 (2012).

[25] Tang B., Park H.E., and Row K.H., Simultaneous Extraction of Flavonoids from Chamaecyparis obtusa Using Deep Eutectic Solvents as Additives of Conventional Extractions Solvents, Journal of Chromatographic Science, 53, 836 (2015).

[26] Durand E., Lecomte J., Villeneuve P., Deep eutectic solvents: Synthesis, application, and focus on lipasecatalyzed reactions. Eur. J. Lipid Sci. Technol. 115, 379 (2013).

[27] Paiva A., Craveiro R., Aroso I., Martins M., Reis R.L., and Duarte A.R.C., Natural Deep Eutectic Solvents-Solvents for the $21^{\text {st }}$ Century, ACS Sustainable Chemistry \& Engineering, 2, 1063 (2014).

[28] García G., Aparicio S., Ullah R., and Atilhan M., Deep Eutectic Solvents: Physicochemical Properties and Gas Separation Applications, Energy Fuels, 29, 2616 (2015).

[29] Blusztajn J.K., Choline, a vital amine, Science, 281, 794 (1998).

[30] Aquilina A., Bampidis V., Bastos M.D.L., Costa L.G., Flachowsky G., Bach A., Scientific opinion on the safety and efficacy of betaine anhydrous as a feed additive for all animal species based on a dossier submitted by Trouw Nutritional International B.V. European Food Safety Authority Journal 11 (5), 3211 (2013).

[31] Zhao B., Xu P., Yang F., Wu H., Zong M., and Lou W., Biocompatible Deep Eutectic Solvents Based on Choline Chloride: Characterization and Application to the Extraction of Rutin from Sophora japonica. ACS Sustainable Chem. Eng. 3, 2746 (2015).

[32] Shahbaz K., Mjalli F.S., Hashim M.A., and AlNashef I.M., Using Deep Eutectic Solvents Based on Methyl Triphenyl Phosphunium Bromide for the Removal of Glycerol from Palm-Oil-Based Biodiesel, Energy Fuels, 25, 2671 (2011).

[33] Shahbaz K., Bagh F.S., Ghareh Mjalli F.S., AlNashef I.M., and Hashim M.A., Prediction of refractive index and density of deep eutectic solvents using atomic contributions. Fluid Phase Equilib., 354, 304 (2013). 
[34] Xu Q., Shen Y., Wang H., Zhang N., Xu S. and Zhang L., Application of response surface methodology to optimise extraction of flavonoids from fructus sophorae. Food Chem., 138, 2122 (2013).

[35] Stalikas C.D., Extraction, separation, and detection methods for phenolic acids and flavonoids. J. Sep. Sci., 30,3268 (2007).

[36] Xiao W., Han L. and Shi B., Microwave-assisted extraction of flavonoids from Radix astragali. Sep. Purif. Technol., 62, 614 (2008).

[37] Chen X.J., Guo B.L., Li S.P., Zhang Q.W., Tu P.F. and Wang Y.T., Simultaneous determination of 15 flavanoids in Epimedium using pressurized liquid extraction and high-performance liquid chromatography J. Chromatogr., A, 1163, 96 (2007).

[38] Tang B., Bi W., Zhang H., Row K.H., Deep Eutectic Solvent-Based HS-SME Coupled with G C for the Analysis of Bioactive Terpenoids in Chamaecyparis obtusa Leaves, Chromatographia 77, 373 (2014).

[39] Theis A.L., Waldack A.J., Hansen S.M., Jeannot M.A., Headspace solvent microextraction. Anal Chem., 73, 5651 (2001).

[40] Choi Y.H., van Spronsen J., Dai Y., Verberne M., Hollmann F., Arends I.W., Witkamp G.J. and Verpoorte R., Are natural deep eutectic solvents the missing link in understanding cellular metabolism and physiology? Plant Physiol., 156(4), 1701 (2011).

[41] Zeng H., Wang Y., Kong J., Nie C. and Yuan Y., Ionic liquid-based microwave-assisted extraction of rutin from Chinese medicinal plants, Talanta, 83, 582 (2010).

[42] Dai Y., Witkamp G.J., Verpoorte R., Choi Y.H. Natural deep eutectic solvents as a new extraction media for phenolic metabolites in Carthamus tinctorius L. Anal. Chem., 85, 6272 (2013).

[43] Bi W., Tian M., Row K.H., Evaluation of alcohol-based deep eutectic solvent in extraction and determination of flavonoids with response surface methodology optimization. J. Chromatogr. A 1285, 22 (2013).

[44] Duan L., Dou L., Guo L., Li P. and Liu E., Comprehensive Evaluation of Deep Eutectic Solvents in Extraction of Bioactive Natural Products ACS Sustainable Chem. Eng. 4, 2405 (2016).

[45] Nisar A., Mamat A.S., Hatim M.I., Aslam M.S., Ahmad M.S., Phytochemical and pharmacognostic study of Catharnthus roseus using deep eutectic solvents. Int. J. Res. Ayurveda Pharm. 7, 141 (2016).

[46] Piemontese L., Perna F.M., Logrieco A., Capriati V. and Solfrizzo M., Deep Eutectic Solvents as Novel and Effective Extraction Media for Quantitative Determination of Ochratoxin A in Wheat and Derived Products, Molecules 22, 121 (2017).

[47] Park H.E., Tang B., Row K.H., Application of Deep Eutectic Solvents as Additives in Ultrasonic Extraction of Two Phenolic Acids from Herba Artemisiae Scopariae Anal. Lett. 47, 1476 (2014).

[48] Tang B., Zhang H., Row K.H. Application of deep eutectic solvents in the extraction and separation of target compounds from various samples. J. Sep. Sci., 38 (6), 1053 (2015).

[49] Li J., Han Z., Zoua Y. and Yu B., Efficient extraction of major catechins in Camellia sinensis leaves using green choline chloride-based deep eutectic solvents, RSC Adv., 5, 93937 (2015).

[50] Xia B., Yan D., Bai, Y., Xie J., Cao Y., Liao D., Lin L., Determination of phenolic acids in Prunella vulgaris $L .:$ a safe and green extraction method using alcohol-based deep eutectic solvents. Anal. Methods 2015, 7, 9354-9364.

[51] Chen Y., Yu M., Zhu Z., Zhang L. and Guo Q., Optimisation of potassium chloride nutrition for proper growth, physiological development and bioactive component production in Prunella vulgaris L. PLoS One, 8(7), e66259 (2013).

[52] Chen Y., Zhu Z., Guo Q., Zhang L. and Zhang X., Variation in concentrations of major bioactive compounds in Prunella vulgaris L. related to plant parts and phenological stages, Biol. Res., 45(2), 171 (2012).

[53] Chen H., Zhang Q., Wang X., Yang J. and Wang Q., Qualitative Analysis and simultaneous Quantification of Phenolic Compounds in the Aerial Parts of Salvia miltiorrhiza by HPLC-DAD and ESI/MS ${ }^{\mathrm{n}}$, Phytochem. Anal., 22, 247 (2011).

[54] Nam M.W., Zhao J., Lee M.S., Jeong J.H., Lee, J. Enhanced extraction of bioactive natural products using tailor-made deep eutectic solvents: application to flavonoid extraction from Flos sophorae. Green Chem. 17 (3), 1718 (2015).

[55] Yao X.H., Zhang D.Y., Duan M.H., Cui Q., Xu W.J., Luo M., Li C.Y., Zu Y.G. \& Fu Y.J. Preparation and determination of phenolic compounds from Pyrola incarnata Fisch. with a green polyols based-deep eutectic solvent, Separation and Purification Technology, 149, 116 (2015). 
[56] Bubalo C M., Radoševic' K., Radojc`ic' Redovnikovic' I., Halambek J., Gaurina Srček V., A brief overview of the potential environmental hazards of ionic liquids. Ecotoxicol. Environ. Saf, 99, 1 (2014).

[57] Wei Z., Qi X., Li T., Luo M., Wang W., Zu Y. \& Fu Y., Application of natural deep eutectic solvents for extraction and determination of phenolics in Cajanus cajan leaves by ultra performance liquid chromatography, Separation and Purification Technology, 149, 237 (2015).

Citation: C. Andrew, "Deep Eutectic Solvents: An Overview of its Application as a "Green" Extractant", International Journal of Advanced Research in Chemical Science (IJARCS), vol. 4, no. 6, pp. 23-30, 2017. http://dx.doi.org/10.20431/2349-0403.0406003

Copyright: (C) 2017 Authors. This is an open-access article distributed under the terms of the Creative Commons Attribution License, which permits unrestricted use, distribution, and reproduction in any medium, provided the original author and source are credited. 